\title{
Avaliação da qualidade química do leite de jumentas da raça Pêga
}

\author{
Chemical evaluation of the quality of Pêga donkey's milk
}

Ivy Craveiro de Sá Ulianaa ${ }^{[a]}$ Barbara Hilgemberg Villela Costa ${ }^{[b]}$, Janaina Socolovski Biava ${ }^{\left[c^{[*}\right.}$

[a] Discente do Curso de Medicina Veterinária do Centro de Ensino Superior dos Campos Gerais (Cescage), Ponta Grossa, PR, Brasil

[b] Médica Veterinária da Propriedade Fazenda São Joaquim, Ponta Grossa, PR, Brasil

[c] Docente Doutora do Curso de Medicina Veterinária do Centro de Ensino Superior dos Campos Gerais (Cescage), Ponta Grossa, PR, Brasil

*Autor correspondente

E-mail: jsbiava@yahoo.com.br

\section{Resumo}

O objetivo deste estudo foi avaliar as características químicas (teores de lactose, proteína, gordura, sólidos totais e contagem de células somáticas) do leite de jumentas da raça Pêga, criadas em sistema de semiconfinamento na região de Ponta Grossa, Paraná. Quinze jumentas com idade média de 9,4 anos foram utilizadas neste estudo. A jumentas foram ordenhadas manualmente a cada 15 dias, com início no $7^{\circ}$ dia após o parto, até os 150 dias de lactação. As amostras de leite foram armazenadas e transportadas em frasco plástico contendo Bronopol ( $45 \mathrm{~mL}$ ), totalizando dez amostras por animal. 0 leite das jumentas apresentou reduzidos teores de gordura (1,28\%), proteína $(2,11 \%)$ e sólidos totais $(10,71 \%)$, e elevados de lactose (6,29\%), quando comparado ao leite bovino. Foram observadas correlações negativas entre os teores de gordura $(-0,332)$, proteína $(-0,620)$ e sólidos totais $(-0,497)$ em função dos dias de lactação, tendo uma queda diária de 0,0056\%, 0,0061\% e 0,0095\%, respectivamente. Entretanto, os teores de lactose apresentaram correlação positiva com os dias de lactação, apresentando um aumento de 0,0015\% diariamente. A contagem de células somáticas aumentou $0,0035 \times 10^{3}$ células por mL a cada dia de lactação. 0 presente estudo demonstrou que o leite de jumenta é caracterizado por baixos níveis de gordura, proteína e sólidos totais, seguindo padrão semelhante ao de outros equídeos.

Palavras-chave: Composição láctea. Equídeos. Lactação. Proteína. Sólidos totais. 


\section{Abstract}

The objective of this study was to evaluate the chemical characteristics (levels of lactose, protein, fat, total solids and somatic cell count) of the milk of jenny of race Pêga, created in the form of a semi-confinement in the region of Ponta Grossa, Paraná, Brazil. Fifteen jennies with an average age of 9.4 years were used in this study. The jennies were milked by hand every 15 days starting at the 7th day after birth, until 150 days of lactation. Milk samples were stored and transported in plastic bottle containing Bronopol ( $45 \mathrm{~mL}$ ), totaling 10 samples per animal. The milk of the jenny showed lower fat (1.28\%), protein (2.11\%) and total solids content (10.71\%) and greater lactose content (6.29\%) compared to the bovine milk. Negative correlations were observed between fat (-0.332), protein (-0.620) and total solids (-0.497) as a function of lactation days, with a daily decrease of $0.0056 \%, 0.0061 \%$ and $0.0095 \%$, respectively. However, the level of lactose showed a positive correlation with the days of lactation, with an increase of $0.0015 \%$ daily. The somatic cell count increased by $0.0035 \times 10^{3}$ cells per $m L$ every day of lactation. The present study demonstrated that the milk of jenny is characterized by low levels of fat, protein and total solids, following similar pattern of other equids'milk.

Keywords: Milk composition. Equidae. Lactation. Protein. Total solids.

\section{Introdução}

A espécie asinina (Equus asinus) tem desempenhado um papel importante junto à humanidade, servindo para tração e transporte, sendo ainda muito importante para a produção de muares (Pugh, 2002). Os jumentos são dotados de grande resistência física quando comparados aos equinos (Torres e Jardim, 1992), podendo sobreviver sob condições adversas (Louro et al., 2006), sendo assim utilizados em regiões onde a agricultura ainda depende da tração animal (Morais et al., 1993; Ragona et al., 2016). Desta forma, os asininos estão associados a um vasto patrimônio de importância social, cultural, econômica e ecológica (Almeida, 2009).

No Brasil, destacam-se três raças de asininos, originárias de animais trazidos pelos colonizadores e do processo de seleção natural: o Jumento Nordestino, o Brasileiro e o Pêga (Mariante e Cavalcante, 2006). A raça Pêga é caracterizada por um porte elegante, altivo e reconhecido potencial genético para andamento marchado, sendo criada exclusivamente para produção de novos reprodutores e também para produção de muares marchadores que possuem, assim como o Jumento Pêga, reconhecido valor comercial em todo o território nacional (Oliveira, 2004).
A última pesquisa realizada sobre a população de asininos no Brasil indicou um efetivo de 902.716 cabeças, sendo que $87,4 \%$ desses animais estão concentrados na região Nordeste (IBGE, 2012). A partir de 2013, os efetivos de asininos e muares deixaram de ser pesquisados devido à ausência de fontes de informação e de registros administrativos para subsidiar as estimativas devido à redução da importância econômica de asininos e muares para o transporte de cargas e pessoas e para a tração de implementos agrícolas (IBGE, 2013). Contudo, a criação desses animais pode ganhar nova perspectiva pela produção leiteira, visto que recentes estudos demonstraram que o leite asinino pode ser utilizado na dieta de crianças com casos de intolerância às proteínas do leite bovino (Caroccio et al., 2000; Cosentino et al., 2015).

O leite, produto da secreção das glândulas mamárias, é um fluido viscoso constituído de uma fase líquida e partículas em suspensão, que possui elevado valor nutritivo, sendo o único alimento que satisfaz às necessidades nutricionais e metabólicas do recém-nascido de cada espécie (Sgarbieri, 1996). Desta forma, a fase de amamentação possui grande importância para o neonato, pois neste período a taxa de crescimento e as exigências nutricionais são mais altas (Cunha, 1991).

Além da importância para a progênie, o leite de 
jumenta poderia ser uma alternativa para crianças alérgicas a certos componentes do leite de vaca, como a $\beta$-lactoblogulina (Trinchese et al., 2015). Ensaios clínicos têm demonstrado que as fórmulas de leite infantil, as quais são em sua maioria à base de leite de vaca, são menos adaptáveis à dieta de pacientes afetados pela alergia à proteína do leite de vaca (CMPA) do que o leite de jumenta (Iacono et al., 1992; Caroccio et al., 2000; Cosentino et al., 2012; Cosentino et al., 2015), devido ao leite asinino possuir baixos níveis de alérgenos caseínicos (Miranda et al., 2004).

Dentre as proteínas lácteas, a concentração de $\beta$-lactoglobulina é maior no leite de vaca (Hambling et al., 1992) do que no leite de jumenta (Vicenzetti et al., 2008), sendo considerada esta proteína a maior responsável por alergias em crianças recémnascidas (Caroccio et al., 1999), visto ser ausente no leite humano (Chatterton et al., 2004; Miranda et al., 2004).

Caroccio et al. (1999) sugeriram a utilização do leite de jumenta na dieta infantil por possuir melhor palatabilidade que as fórmulas de leite nutracêutico. Trinchese et al. (2015) demonstram o efeito hipolipêmico capaz de influenciar a homeostase metabólica e o estado inflamatório, modulando a função mitocondrial e a composição microbiana intestinal. Além disso, o leite asinino contém altas concentrações de aminoácidos essenciais (Taha e Kielwein, 1990), apresentando maiores níveis de valina e lisina quando comparado ao leite de vacas holandesas, búfalas, cabras, ovelhas, fêmeas de camelo e éguas (Abd-Elsalam et al., 1992).

o leite asinino, quando comparado ao de ruminantes, apresenta uma considerável quantidade de ácidos graxos insaturados, importantes para prevenção de doenças inflamatórias cardiovasculares (Chiofalo et al., 2001; Miranda et al., 2004; Cosentino et al., 2015). Também contém altas concentrações de lisozima, um agente antimicrobiano natural, que pode funcionar no trato digestivo do bebê, reduzindo a incidência de infecções gastrointestinais (Businco et al., 2000; Miranda et al., 2004; Cosentino et al., 2015).

Além da utilização nutricional, o leite asinino pode ser utilizado para produção de cosméticos, já que o mercado atual tem buscado produtos à base de ingredientes naturais (Parente et al., 2011), e este leite possuir proteínas e outros componentes relacionados à capacidade de absorção e retenção de água, obtendo-se um elevado grau de hidratação da pele e previnindo a degradação das células epidérmicas (Simos et al., 2011).

Devido a todas essas vantagens, países como a China vêm se esforçando para aumentar a produção de leite asinino, estabelecendo centros de reprodução para jumentas (Guo et al., 2007), alcançando uma produção anual de mais de 40 mil toneladas (Yang et al., 2006). Na Itália, onde já são comercializados produtos à base de leite asinino, há incentivo para a produção desse tipo de leite na região sul do país (Cosentino et al., 2012). 0 leite asinino também é utilizado principalmente em países onde essa espécie animal é tradicionalmente criada, especialmente na Ásia, África e Europa Oriental (Faye e Konuspayeva, 2012).

Considerando o seu perfil nutricional único, o leite de jumenta poderia ser explorado para suprir exigências nutricionais de pessoas intolerantes aos componentes de outros tipos de leites e também como fonte de renda para os produtores de asininos (Cosentino et al., 2012), aumentando a importância econômica desta espécie na produção pecuária. Porém, informações sobre a composição deste leite são extremamente limitadas, principalmente devido às dificuldades relacionadas com as técnicas de ordenha e os erros de amostragem (Oftedal e Jenness, 1988; Salimei et al., 2000).

Devido à escassez de estudos relacionados à composição e à qualidade do leite de asininos, objetiva-se com este trabalho avaliar as características químicas (teores de lactose, proteína, gordura, sólidos totais e contagem de células somáticas) do leite de jumentas da raça Pêga, criadas em sistema de semi-confinamento no município de Ponta Grossa, Paraná.

\section{Material e métodos}

0 presente experimento foi realizado de julho de 2013 a março de 2014, na Fazenda São Joaquim, situada em Ponta Grossa, Paraná, nas seguintes coordenadas geográficas: latitude $-25^{\circ} 05^{\prime} 42^{\prime \prime}$ e longitude $-50^{\circ} 09^{\prime} 43^{\prime \prime}$. O município possui clima subtropical úmido mesotérmico (Cfb), segundo 
a classificação de Köppen e Geiger (1928), apresentando temperatura média abaixo de $18^{\circ} \mathrm{C}$ no mês mais frio, com verões frescos e temperatura média abaixo de $22^{\circ} \mathrm{C}$ no mês mais quente, não havendo estação seca definida (Prefeitura Municipal de Ponta Grossa, 2007).

Foram utilizadas quinze jumentas da raça Pêga, com idades variando de 4 a 17 anos (média $=9,4$ anos; moda: bimoidal $=4$ e 17), sendo quatro primíparas e onze multíparas. Foram utilizadas apenas fêmeas saudáveis, que não apresentassem febre e nem sintomas de dor ou incômodo durante a ordenha.

As jumentas foram mantidas em sistema de semi-confinamento, recebendo $2,5 \mathrm{~kg}$ de ração/dia, equivalente a $1 \%$ do peso vivo (composição da ração na Tabela 1), 1,5 kg de aveia hidratada e sal mineral Kromium $^{\circledR}$ e feno de azevém (Lollium multifolium) ad libitum no período que permaneciam nas baias. Todos os animais foram alimentados em comedouros coletivos. As jumentas eram soltas diariamente em piquetes onde pastejavam à vontade, sendo que no período de julho a agosto de 2013 os piquetes continham azevém, e de setembro de 2013 a março de 2014 predominava pastagem nativa.

Tabela 1 - Composição da ração fornecida às jumentas da raça Pêga na Fazenda São Joaquim, Ponta Grossa/PR

\begin{tabular}{|c|c|}
\hline Ingredientes & Quantidade (kg) \\
\hline Aveia com casca & 40 \\
\hline Cevada Moída & 26 \\
\hline Farelo de soja & 10 \\
\hline Casquinha de soja & 20 \\
\hline Sal Mineral Kromium ${ }^{\circledR}$ & 2 \\
\hline Calcário Calcítico Calpar & 1,5 \\
\hline Suplemento Kromium Mix ${ }^{\circledR}$ & 0,5 \\
\hline Total & 100 \\
\hline
\end{tabular}

As coletas do leite foram realizadas por ordenha manual diretamente em um frasco plástico de $45 \mathrm{~mL}$ com conservante Bronopol, sendo que a primeira coleta foi realizada no sétimo dia após o parto, e então foram feitas a cada quinze dias até o desmame, totalizando dez amostras por animal durante os 150 dias de lactação. A contenção das jumentas para a coleta do leite foi feita apenas com o uso de cabresto. Antes de cada coleta, as tetas das jumentas, bem como as mãos do ordenhador, foram higienizados com álcool 70\%. Após as coletas, as amostras de leite foram enviadas ao Laboratório do Programa de Análise de Rebanhos Leiteiros do Paraná (PARLPR), da Associação Paranaense de Criadores de Bovinos da Raça Holandesa (APCBRH), localizado em Curitiba, Paraná.

As amostras foram analisadas para a determinação dos valores de lactose, proteína, gordura, sólidos totais e contagem de células somáticas (CCS). Os valores de lactose, proteína, gordura e sólidos totais foram determinados pelo método de infravermelho (International IDF Standar 141C; 2000), e a CCS por citometria de fluxo (International IDF Standar 148-2; 2006).

Os dados foram submetidos à análise de correlação de Pearson e de covariância contínua. As análises foram realizadas pelo programa MINITAB 16 (2014).

\section{Resultados e discussão}

Os valores médios da composição do leite expressos em porcentagem de gordura, proteína, sólidos totais e lactose podem ser observados na Tabela 2. Observou-se que o leite de jumenta apresenta reduzidos teores de gordura, proteína e sólidos totais, e elevados teores de lactose quando comparado ao leite bovino (Tabela 3). 0 mesmo resultado foi relatado por Cosentino et al. (2012; 2015). Cavallarim et al. (2015) encontraram uma média de $1,5 \%$ de proteína e $0,1 \%$ de gordura no leite de jumenta, valores inferiores aos obtidos neste estudo para ambos os componentes.

Salimei et al. (2004), analisando a composição do leite de duas raças de asininos (Martina Franca e Ragusana) alimentadas com $10 \mathrm{~kg}$ de feno/dia $(\mathrm{PB}=9 \%)$ e $2,5 \mathrm{~kg}$ de concentrado/dia (PB $=15 \%)$, observaram valores médios de $0,38 \%(0,10 \%$ $1,40 \%)$ para gordura, $1,72 \%(1,25 \%-2,18 \%)$ para proteína, 6,88\% $(6,03 \%-7,28 \%)$ para lactose, e $8,84 \%(8,45 \%$ - 9,13\%) para sólidos totais. Coppola et al. (2002) também avaliaram o leite de jumentas da raça Martina Franca, relatando valores inferiores 
para sólidos totais e semelhantes para gordura, proteína e lactose aos obtidos neste estudo: 8,86 $( \pm 0,15)$ para sólidos totais, $0,52( \pm 0,12)$ para gordura, $1,66( \pm 0,08)$ para proteína e $7,03( \pm 0,10)$. para lactose.

Tabela 2 - Composição média ( \pm desvio padrão) do leite de jumentas da raça Pêga na Fazenda São Joaquim, Ponta Grossa/PR

\begin{tabular}{lc}
\hline Componentes & Jumenta Pêga \\
\hline Proteína (\%) & $2,11( \pm 0,36)$ \\
Gordura (\%) & $1,28( \pm 0,60)$ \\
Lactose (\%) & $6,29( \pm 0,22)$ \\
Sólidos Totais (\%) & $10,71 \pm 0,67)$ \\
CCS $\times 10^{3} / \mathrm{mL}$ & $0,785( \pm 0,65)$ \\
\hline
\end{tabular}

Nota: CCS = Contagem de células somáticas.

Os teores de proteína foram superiores aos encontrados por Guo et al. (2007), os quais obtiveram valores entre $1,5-1,8 \%$, porém semelhantes para gordura e lactose, os quais, para esses autores, variaram entre $0,3-1,8 \%$ e 5,8$7,4 \%$, respectivamente, quando avaliaram o leite de jumentas com idades variando entre 4 a 14 anos, alimentadas com dieta a base de farelo de soja e de milho, óleo, fermentado de palha de milho, trevo e palha de trigo $(\mathrm{PB}=13 \%$; $\mathrm{EE}=2,24 \% ; \mathrm{FB}=18,97 \%$; $\mathrm{ED}=16,28 \mathrm{MJ} / \mathrm{kg}$ ).

Os resultados demonstraram semelhança entre o leite da jumenta Pêga e o de outros equídeos, o que é coerente com os resultados obtidos por Oftedal e Jenness (1988), que também observaram semelhança na composição do leite de asininos, equinos e zebras.

Sabe-se que as características físico-químicas do leite sofrem variações de uma espécie animal para outra, inclusive entre diferentes raças. A produção e a composição do leite também podem ser influenciadas por vários fatores como idade, ordem de parto, peso vivo, dieta e condições ambientais (Santos et al., 2005). Esses fatores podem explicar a variação entre os resultados obtidos neste estudo e os obtidos por outros autores.

Quando comparado ao leite humano, o de jumenta é semelhante quanto aos teores de lactose, porém possui menor teor de gordura e sólidos totais, e maiores teores de proteina (Tabela 3). No entanto, Paolicelli (2005) argumentou que o leite de jumenta apresenta perfil proteico semelhante ao leite humano e, devido a isso, pode ser adequado para consumo infantil.

Segundo Salimei et al. (2004), o leite asinino possui menor concentração de gordura do que o humano, porém a fração lipídica deste leite é comparável a do leite da mulher, já que é caracterizada por níveis elevados de ácido linoleico e ácido linolênico. Silva et al. (2007) relataram que o leite da mulher possui em média 1,12\% $( \pm 0,28)$ de proteína e 1,38\% $( \pm 0,60)$ de gordura, valores semelhantes ao leite de jumentas no que se refere à gordura, contudo com menor teor de proteína.

Estas diferenças entre o leite de jumentas, humano e de vacas se devem principalmente ao tipo de dieta que estes animais consomem (Ragona et al., 2016).

0 alto teor de lactose do leite asinino é um fator benéfico para introduzi-lo na dieta infantil (Ragona et al., 2016), já que, segundo Schaafsma (2003), a lactose é responsável pela boa palatabilidade do leite, além de ser importante para a otimização da absorção intestinal de cálcio, a qual é essencial para a mineralização óssea em crianças.

Tabela 3 - Comparação entre a composição do leite de jumentas da raça Pêga e a composição do leite de égua, de vaca e da mulher

\begin{tabular}{lcccc}
\hline Espécie & Gordura (\%) & Proteína (\%) & Lactose (\%) & Sólidos totais (\%) \\
\hline Jumenta Pêga & $0,68-1,88$ & $1,75-2,47$ & $6,07-6,51$ & $10,04-11,38$ \\
Égua & $0,5-2,0^{1}$ & $1,5-2,8^{1}$ & $5,8-7,0^{1}$ & $9,3-11,6^{1}$ \\
Vaca & $3,5-3.9^{1}$ & $3,1-3,8^{1}$ & $4,4-4,9^{1}$ & $12,5-13,0^{1}$ \\
Mulher & $3,5-4.0^{1}$ & $0,9-1,7^{1}$ & $6,3-7,0^{1}$ & $11,7-12,9^{1}$ \\
\hline
\end{tabular}

Nota: ${ }^{1}$ Guo et al. (2007). 
Tabela 4 - Correlações entre os componentes do leite de jumentas da raça Pêga e os dias de lactação, Fazenda São Joaquim, Ponta Grossa/PR

\begin{tabular}{lccccc}
\hline Item & Dias de lactação & Gordura (\%) & Proteína (\%) & Lactose (\%) & Sólidos totais (\%) \\
\hline Gordura (\%) & $-0,332^{* * *}$ & & & & \\
Proteína (\%) & $-0,620^{* * *}$ & $0,394^{* * *}$ & & \\
Lactose (\%) & $0,194^{*}$ & $-0,441^{* * *}$ & $-0,289^{* *}$ & \\
Sólidos totais (\%) & $-0,497^{* * *}$ & $0,887^{* * *}$ & $0,656^{* * *}$ & $-0,336^{* * *}$ & \\
CCS $10^{3} / \mathrm{mL}$ & $0,218^{*}$ & $-0,143 \mathrm{~ns}$ & $-0,021 \mathrm{~ns}$ & $0,026 \mathrm{~ns}$ & $-0,134 \mathrm{~ns}$ \\
\hline
\end{tabular}

Nota: Correlação de Pearson ao nível de significância indicado por ns $P>0,05,{ }^{*} P \leqslant 0,05,{ }^{* *} P \leqslant 0,01 e^{* * *} P \leqslant 0,001$. CS $=$ Contagem de células somáticas.

Na Tabela 4 pode ser observada a correlação entre os componentes do leite e o período de lactação das jumentas da raça Pêga. Os resultados indicam uma correlação negativa entre os teores de gordura $(-0,332)$, proteína $(-0,620)$ e sólidos totais $(-0,497)$ em função dos dias de lactação, indicando que estes componentes decrescem durante os 150 dias de lactação, como pode ser observado nas Figuras 1,2 e 3, respectivamente. Os teores de lactose e a CCS apresentaram uma correlação positiva com os dias de lactação (Tabela 4), demonstrando aumento desses até o fim da lactação, como pode ser observado nas Figuras 4 e 5.

Há uma redução diária dos teores de gordura, proteína e sólidos totais de 0,0056\%, 0,0061\% e 0,0095\% até o término da lactação, respectivamente, e aumento diário de 0,0015\% dos teores de lactose e de $0,0035 \%$ da contagem de células somáticas (Tabela 5).

O aumento da CCS durante a lactação pode estar associado à maior contaminação do úbere em função da amamentação pela progênie e/ou pela contaminação do ambiente onde permaneciam as jumentas.

A CCS do leite de jumenta Pêga é baixa quando comparada a do leite de vaca, o que pode ser explicado pela alta concentração de lisozima no leite asinino (Cavallarim et al., 2015), uma enzima com propriedade bactericida que hidrolisa os polissacarídeos da parede celular bacteriana, inibindo seu desenvolvimento (Chiavari et al., 2005).

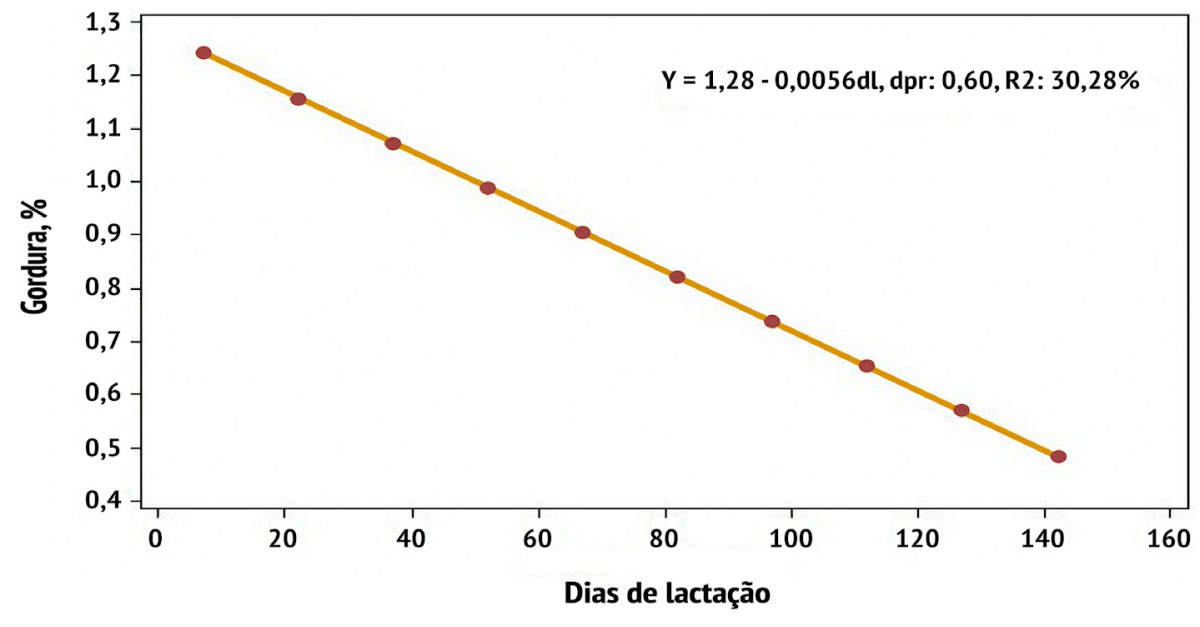

Figura 1 - Teor de gordura no leite de jumentas da raça Pêga durante os 150 dias de lactação.

Nota: $d l=$ dias de lactação; $\mathrm{dpr}=$ desvio padrão residual. 

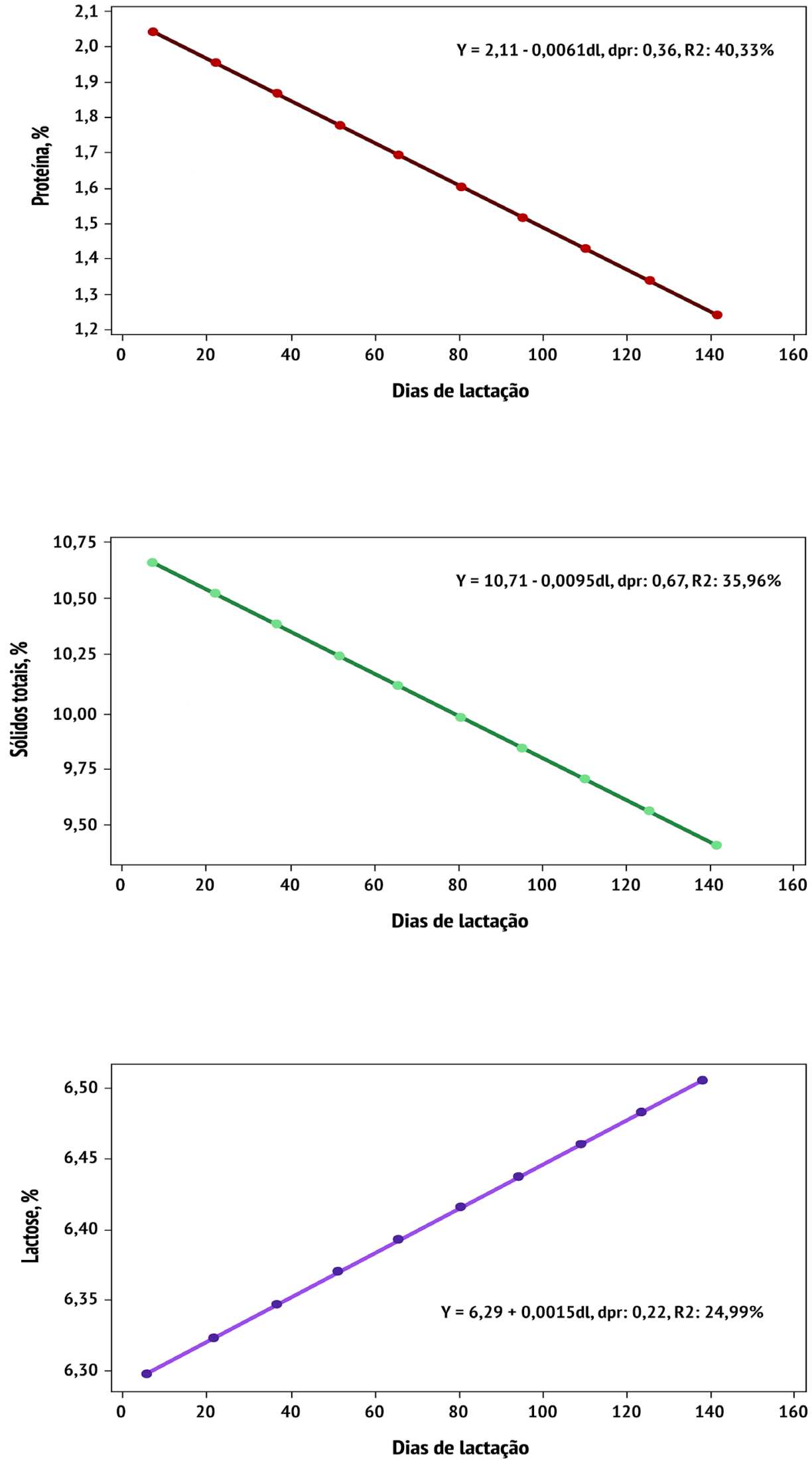

Figura 2 - Teor de proteína no leite de jumentas da raça Pêga durante os 150 dias de lactação.

Nota: $d l=$ dias de lactação; $\mathrm{dpr}=$ desvio padrão residual.

Figura 3 - Teor de sólidos totais no leite de jumentas da raça Pêga durante os 150 dias de lactação.

Nota: $\mathrm{dl}=$ dias de lactação; $\mathrm{dpr}=$ desvio padrão residual.

Figura 4 - Teor de lactose no leite de jumentas da raça Pêga durante os 150 dias de lactação.

Nota: $\mathrm{dl}=$ dias de lactação; $\mathrm{dpr}=$ desvio padrão residual. 


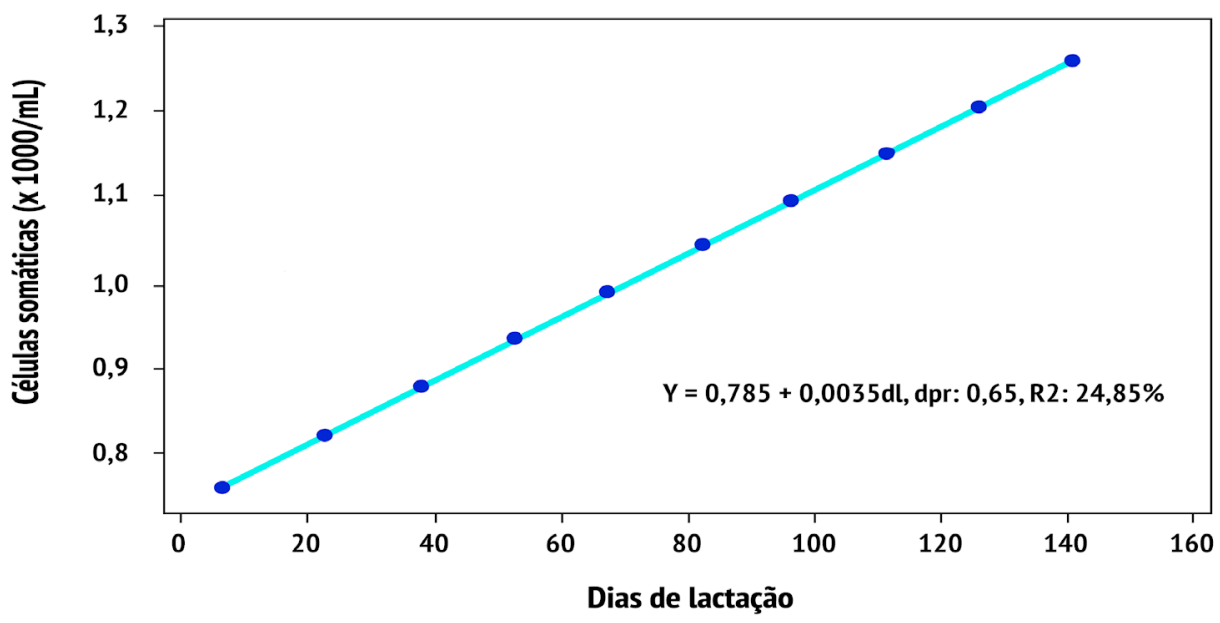

Figura 5 - Contagem de células somáticas no leite de jumentas da raça Pêga durante os 150 dias de lactação.

Nota: $\mathrm{dl}=$ dias de lactação; $\mathrm{dpr}=$ desvio padrão residual.

Tabela 5 - Equações de regressão para os components do leite de jumentas da raça Pêga na Fazenda São Joaquim, Ponta Grossa, PR

\begin{tabular}{lccc}
\hline Componentes & \multicolumn{1}{c}{ Equação } & dpr $^{\mathbf{1}}$ & R2 (\%) \\
\hline Gordura (\%) & $\mathrm{Y}=1,28-0,0056 \mathrm{dl}$ & 0,60 & 30,28 \\
Proteína (\%) & $\mathrm{Y}=2,11-0,0061 \mathrm{dl}$ & 0,36 & 40,33 \\
Lacotose (\%) & $\mathrm{Y}=6,29+0,0015 \mathrm{dl}$ & 0,22 & 24,99 \\
Sólidos totais (\%) & $\mathrm{Y}=10,71-0,0095 \mathrm{dl}$ & 0,67 & 35,96 \\
$\operatorname{CCS}\left(\times 10^{3} / \mathrm{mL}\right)$ & $\mathrm{Y}=0,785+0,0035 \mathrm{dl}$ & 0,65 & 24,85 \\
\hline
\end{tabular}

Nota: ${ }^{1}$ Desvio padrão residual; $\mathrm{dl}=$ dias de lactação; $\mathrm{CCS}=$ Contagem de células somáticas.

Salimei et al. (2004) e Copola et al. (2002) também observaram uma contagem bacteriana e CCS consideradas baixas, podendo ser explicadas pela alta concentração de lisozima. Porém, Copola et al. (2002) relataram que bactérias lácticas conseguem se desenvolver com a presença desta enzima, concluindo que o leite de jumenta poderia ser utilizado para produção de bebida láctea. Cosentino et al. (2015) observaram uma maior CCS durante o verão, aliada a um maior $\mathrm{pH}$ do leite neste período.

Guo et al. (2007) observaram queda dos teores de proteína até os 120 dias de lactação, e depois aumento deste componente até os 180 dias. Os mesmos autores relataram uma ampla variabilidade no teor de gordura, contendo uma porcentagem baixa $(0,5 \%)$ até o 15 o dia, depois aumento até o $105^{\circ}$ dia, atingindo um pico de 1,40\%, decréscimo até os 120 dias, e novamente aumento até o final da lactação. E para lactose, observaram uma concentração constante deste componente até os 180 dias de lactação.

Salimei etal. (2004) observaram queda dos teores de proteína até o 45으 dia de lactação, seguido por um aumento até o 75으 dia, e posterior declínio deste componente até os 135 dias. Os mesmos autores também relataram oscilação da concentração de gordura, uma vez que a mesma declinou até os 45 dias de lactação, depois aumentou atingindo o pico aos 105 dias, e posteriormente decaiu até o fim da lactação.

Os resultados obtidos por Guo et al. (2007) e Salimei et al. (2004) apresentaram oscilação entre queda e aumento dos teores de proteína e gordura e concentração constante de lactose até o fim da lactação, demonstrando que as concentrações dos componentes químicos do leite de jumenta podem não seguir um padrão linear de aumento de lactose e queda de gordura e proteína até o final da lactação, diferindo-se dos resultados obtidos neste trabalho.

Cosentino et al. (2015) também encontratam oscilação dos teores de proteina, que dimiuiram até os 90 dias e depois aumentaram até o final da lactação. Já os resultados obtidos neste trabalho demonstram queda linear nos teores de gordura e proteína e aumento linear no teor de lactose até os 150 dias de lactação.

O leite de jumenta Pêga possui comportamento 
semelhante ao leite equino, como relatado por Burns et al. (1992) em estudo sobre o leite de éguas da raça Quarto de Milha, em que os teores dos constituintes químicos do leite, com exceção da lactose, diminuíram durante a lactação. Santos et al. (2005), avaliando o leite de éguas da raça Mangalarga Marchador, observaram comportamento semelhante para os teores de proteína e gordura, porém a lactose aumentou até o $40^{\circ}$ dia de lactação e depois declinou com tendência linear até o $160^{\circ}$ dia.

Cosentino et al. (2015) observaram que a presença do potro e o estágio de lactação influenciaram no conteúdo de gordura e proteína do leite. Os autores relataram que os valores de alguns componentes lácteos como proteína, gordura e minerais são maiores no início da lactação, devido a esta fase ser de extrema importância para o crescimento inicial da progênie.

A oscilação dos componentes químicos do leite demonstra que o principal fator fisiológico envolvido com as variações dos constituintes lácteos é o estágio de lactação (Voutsinas et al., 1990; Rota et al., 1993; Zeng et al., 1997; Gomes et al., 2004; Cosentino et al., 2012).

\section{Conclusão}

O leite de jumentas da raça Pêga é caracterizado por alto teor de lactose e baixo teor de gordura em comparação ao leite humano e leite de ruminantes. As características de qualidade do leite de jumenta são reconhecidas pela literatura e sustentam seu uso em casos de alergias alimentares. As variações dos componentes químicos do leite de jumenta ao longo da curva de lactação se assemelham às das outras espécies equídeas, visto que os constituintes do leite, com exceção da lactose, decresceram até os 150 dias de lactação.

\section{Referências}

Almeida LD. Diversidade genética de raças asininas criadas no Brasil, baseada na análise de locos microssatélites e DNA mitocondrial [dissertação]. Brasília: Universidade de Brasília; 2009.
Burns HD, Gibbs PG, Potter GD. Milk-energy production by lactating mares. J Equine Vet Sci. 1992;10(2):118-20.

Businco L, Giampietro PG, Lucenti P, Lucaroni F, Pini C, Di Felice G, et al. Allergenicity of mare's milk in children with cow's milk allergy. J Allergy Clin Immunol. 2000;105(5):1031-4.

Carroccio A, Cavataio F, Iacono G. Cross-reactivity between milk proteins of different animals. Clin Exp Allergy. 1999;29(8):1014-6.

Carroccio A, Cavataio F, Montalto GD, D’Amico D, Alabrese $\mathrm{L}$, Iacono G. Intolerance to hydrolysed cow's milk proteins in infants: clinical characteristics and dietary treatment. Clin Exp Allergy. 2000;30(11):1597-603.

Cavallarin L, Giribaldi M, Soto-Del Rio MD, Valle E, Barbarino G, Gennero MS, et al. A survey on the milk chemical and microbiological quality in dairy donkey farms located in North Western Italy. Food Control. 2015;50:230-5.

Chatterton DEW, Rasmussen JT, Heegaard CW, Sørensen ES, Petersen TE. In vitro digestion of novel milk protein ingredients for use in infant formula: Research on biological functions. Trends Food Sci Technol. 2004;15(7-8):373-83.

Chiavari C, Coloretti F, Nanni M, Sorrentino E, Grazia L. Use of donkey's milk for a fermented beverage with lactobacilli. Dairy Sci Tecnol. 2005;85(6):481-90.

Chiofalo B, Salimei E, Chiofalo L. Ass's milk: Exploitation of an alimentary resource. Riv Folium. 2001;1(Suppl. 3):235-41.

Coppola R, Salimei E, Succi M, Sorrentino E, Nanni M, Ranieri P, et al. Behaviour of Lactobacillus rhamnosus strains in ass's milk. Ann Microbiol. 2002;52:55-60.

Cosentino C, Paolino R, Freschi P, Calluso AM. Short communication: jenny milk production and qualitative characteristics. J Dairy Sci. 2012;95(6):2910-5.

Cosentino C, Paolino R, Musto M, Freschi P. Innovative Use of Jenny Milk from Sustainable Rearing. In: Vastola A (Ed). The Sustainability of Agro-Food and Natural Resource Systems in the Mediterranean Basin. Springer Open; 2015. p.113-32. Disponível em: https://tinyurl.com/j87cqkr. 
Cunha TJ. Horse feeding and nutrition. 2th ed. San Diego: Academic Press; 1991.

Faye B, Konuspayeva G. The sustainability challenge to the dairy sector. The growing importance of non-cattle milk production wordwide. Int Dairy J. 2012;24(2):50-6.

Gibbs PG, Potter GD, Blake RW, McMullan WC. Milk production of Quarter horse during 150 days of lactation. J Anim Sci. 1982;54(3):496-9.

Gomes V, Libera AMMPD, Madureira KM, Araújo WP. Influência do estado de lactação na composição do leite de cabras (Capra hircus). Braz J Vet Res Anim Sci. 2004;41(5);340-2.

Guo HY, Pang K, Zhang XY, Zhao l, Chen SW, Dong ML, et al. Composition, physiochemical properties, nitrogen fraction distribution, and amino acid profile of donkey milk. J Dairy Sci. 2007;90(4):1635-43.

Hambling SG, Mcalpine AS, Sawyer l. Beta-lactoglobulin. In: Fox PF (Ed). Advanced Dairy Chemistry: 1. Proteins. London: Elsevier Applied Science; 1992. p.141-90.

Iacono $\mathrm{G}$, Carroccio A, Cavataio F, Montalto G, Soresi M, Balsamo V. Use of ass' milk in multiple food allergy. J Pediatr Gastroenterol Nutr. 1992;14(2):177-81.

Instituto Brasileiro de Geografia e Estatística - IBGE. Prod Pec Munic. 2012;40:1-71.

Instituto Brasileiro de Geografia e Estatística - IBGE. Prod Pec Munic. 2013;41:1-108.

Köppen W, Geiger R. Klimate der Erde. Gotha: Verlag Justus Perthes; 1928 . Wall-map $150 \mathrm{~cm} \times 200 \mathrm{~cm}$.

Louro MFC, Dias RVC, Soto-Blanco B. Avaliação do fluido peritoneal de asininos. Arq Bras Med Vet Zootec. 2006;58(5):955-8.

Mariante AS, Cavalcante N. Animais do Descobrimento: Raças domésticas da história do Brasil. Distrito Federal: Embrapa; 2006.

Miranda G, Mahé Mf, Leroux C, Martin P. Proteomic tools to characterize the protein fraction of Equidae milk.
Proteomics. 2004;4(8):2496-509.

MINITAB. Minitab Inc., Versão 15. 15.1. 2007.

Morais RN, Mucciolo RG, Viana WG. Biologia reprodutiva de jumentos. I. Biometria testicular e comportamento sexual durante a colheita de sêmen. Braz J Vet Res Anim Sci. 1993;30(1):47-50.

Oftedal OT, Jenness R. Interspecies variation in milk composition among horses, zebras and asses (Perissodactyla: Equidae). J Dairy Res. 1988;55:57-66.

Oliveira VB. Uma visão técnica e pedagógica sobre os muares [dissertação]. Rio de Janeiro: Universidade Federal Rural do Rio de Janeiro; 2004.

Paolicelli F. Impiego del Latte di Asina in Campo Medico, Alimentare e Cosmetico. In: $1^{\circ}$ Convegno Nazionale sull' Asino Grosseto; 27 - 28 maio 2005.

Parente ME, Manzoni AV, Ares G. External preference mapping of commercial antiaging creams based on consumers' responses to a check-all-that-apply question. J Sens Stud. 2011;26(2):158-66.

Prefeitura de Ponta Grossa. Secretaria Municipal de Planejamento. Relatório de Avaliação Ambiental RAA. Ponta Grossa, 2007. 47 p.

Pugh DG. Donkey Reproduction. AAEP Proceedings. 2002;48:113-4.

Ragona G, Corrias F, Benedetti M, Paladini M, Salari F, Altomonte L, et al. Amiata donkey milk chain: animal health evaluation and milk quality. Ital J Food Saf. 2016;5(3):5951.

Rota AM, Rodríguez P, Rojas A, Martin L, Tovar J. Evolucion de la cantidad y calidad de la leche de cabra Verata a lo largo de la lactacion. Arch Zootec. 1993;42(157):137-46.

Salimei E, Belli Blanes R, Marano A, Ferretti E, Varisco G, Casamassima D. Produzione quanti-qualitativa di latte di asina: risultati di due lattazioni. In: 35th Int Symp Società Italiana per il progres-so della Zootecnia; 2002 maio 25. Ragusa Ibla, Itália. p. 315-22. 
Salimei E, Fantuz F, Coppola R, Chiofalo B, Polidori P, Varisco G. Composition and characteristics of ass's milk. Anim Res. 2004;53(1):67-78.

Santos EM, Almeida FQ, Vieira AA, Pinto LFB, Corassa A, Pimentel RRM, et al. Lactação em éguas da raça mangalarga marchador: produção e composição do leite e ganho de peso dos potros lactentes. R Bras Zootec. 2005;34(2):627-34.

Schaafsma G. Nutritional significance of lactose and lactose derivatives. In: Roginski H, Fuquay JW, Fox PF. Encyclopedia of Dairy Science. London: Academic Press; 2003. p.1529-33.

Sgarbieri VC. Proteínas em alimentos protéicos: propriedades-degradações-modificações. São Paulo: Varela; 1996.

Silva RC, Escobedo JP, Gioielli LA, Quintal VS, Ibidi SM, Albuquerque EM. Composição centesimal do leite humano e caracterização das propriedades físicoquímicas de sua gordura. Quim Nova. 2007;30(7):1535-8.

Simos Y, Metsios A, Verginadis I, D’Alessandro AG, Loiudice P, Jirillo E, et al. Antioxidant and anti-platelet properties of milk from goat, donkey and cow: an in vitro, ex vivo and in vivo study. Int Dairy J. 2011;21(11):901-6.

Taha NM, Kielwein G. Pattern of peptide-bound and free amino acids in camel, buffalo and ass milk. Milchwissenschaft. 1990;45:22-5.

Torres AP, Jardim WR. Criação do cavalo e de outros equinos. $2^{\circ}$ ed. São Paulo: Nobel; 1992.

Trinchese G, Cavaliere G, Canani RB, Matamoros S, Bergamo P, DeFilippo C, etal. Human, donkey and cow milk differently affects energy efficiency and inflammatory state by modulating mitochondrial function and gut microbiota. J Nutr Biochem. 2015;26(11):1136-46.

Ulrrey DE, Struthers RD, Hendricks DG, Brent BE. Composition of mares' milk. J Anim Sci. 1966;25:217-21.

Vicenzetti S, Polidori P, Mariani P, Cammentoni N. Donkey's milk protein fractions characterization. Food Chem. 2008;106(2):640-9.
Voutsinas L, Pappas C, Katsiari M. The composition of Alpine goat's milk during lactation in Greece. J Dairy Sci. 1990;57(1):41-51.

Yang HF, Ma L, Zhao XG, Su DQ. Studies on the development and exploitation of donkey milk. Chin Food Nutr. 2006;4:22-4

Zeng SS, Escobar EN, Popham T. Daily variations in somatic cell count, composition, and production of Alpine goat milk. Small Rumin Res. 1997;26(3):253-60.

Recebido em: 23/05/2016 Received in: 05/23/2016

Aprovado em: 24/02/2017 Approved in: 02/24/2017 